
NBSIR 77-1405

\section{DETERMINATION AND VERIFICATION OF THERMAL RESPONSE FACTORS FOR THERMAL CONDUCTION APPLICATIONS}

Bradley A. Peavy

Building Thermal and Service Systems Division Center for Building Technology National Engineering Laboratory National Bureau of Standards

Washington, D.C. 20234

Final Report

April 1978

U.S. DEPARTMENT OF COMMERCE, Juanita M. Kreps, Secretary

Dr. Sidney Harman, Under Secretary

Jordan J. Baruch, Assistant Secretary for Science and Technology

NATIONAL BUREAU OF STANDARDS, Ernest Ambler, Director 

Bradley A. Peavy

\section{ABSTRACT}

New formulas for calculating thermal response factors for multiple-1ayer construction have been developed by a rigorous derivation. A comparison was made of the time for computation between the presently used matrix algebra method and the method given in this paper. Results were obtained using the new method in one-fiftieth to one-half of the computational time necessary to obtain solutions from the matrix algebra method.

Comparisons with another analytical method were performed to verify the accuracy of the response-factor technique.

Key Words: Dynamic conduction heat transfer; heat transfer; thermal response factor; verification. 

DETERMINATION AND VERIFICATION OF THERMAL RESPONSE FACTORS

FOR THERMAL CONDUCTION APPLICATIONS

by

Bradley A. Peavy

1. INTRODUCTION

The analytical solutions needed to describe temperature or heat flow for steady periodic or transient conduction heat transfer in multi-layer walls, ceilings and floors are quite complicated and are not available for nonlinear conditions such as thermal radiation at surfaces and time-dependent changes in surface film coefficients. It has therefore been expedient to employ "approximation" methods by which non-linear conditions may be satisfied. One such method, which is the result of an analytical formulation, is termed the "response-factor method," and solves for temperatures or heat flows of multi-layer constructions based on the past temperature history.

A response-factor method defined by Kusuda [1]* uses overlapping triangular pulses to compute response factors for a particular construction. These response factors are then used to determine temperatures and heat flows in response to previously occurring events. In order to handle multi-layer constructions for solution of response factors by computers, a matrix algebra was developed for an arbitrary number of layers. There are some inherent difficulties in using this approach, in that the calculation of response factors can be quite time consuming because certain functions

* See references cited at end of text 
are not well suited for efficient calculation. A portion of this paper will be devoted to the development of equations which allow for increased computational efficiency. The algorithms presented are sufficient for the determination of up to a seven layer composite, which is probably more than sufficient for possible building constructions.

Unfortunately, the accuracy of the temperatures and heat flows values calculated by response-factor methods has received very little verification. Although it is well known that the thermal properties of building materials are not as well defined as they should be, this is no excuse for not knowing the error incurred by the use of an approximate method for whatever thermal properties may be assigned to a particular program for solution. A portion of this paper will be devoted to a comparison between numerical results from an analytical solution and results from calculations using the response-factor technique.

\section{ANALYSIS}

For one-dimensional heat flow in an individual layer of one or more parallel layers, the partial differential equation is given by

$$
\frac{\partial^{2} v_{m}}{\partial x^{2}}=\frac{1}{\alpha_{m}} \frac{\partial v_{m}}{\partial t}
$$

where $v_{m}$ is the temperature potential above a datum plane, $x$ is a dimension along which heat is flowing, $\alpha_{m}$ is the thermal diffusivity of the layer material, and $t$ is the time. For continuity of temperature and heat flow 
between layers, perfect contact is assumed, i.e.,

$$
v_{m-1}=v_{m}
$$

and

$$
\mathrm{K}_{\mathrm{m}-1} \frac{\mathrm{d} \nu_{\mathrm{m}-1}}{\mathrm{dx}}=\mathrm{K}_{\mathrm{m}} \frac{\mathrm{d} \nu_{\mathrm{m}}}{\mathrm{dx}}
$$

where $\mathrm{K}_{\mathrm{m}}$ is the thermal conductivity of the respective layer. Applying the Laplace transform to (1) gives

$$
\frac{\mathrm{d}^{2} \bar{v}_{\mathrm{m}}}{\mathrm{dx} \mathrm{x}^{2}}=\mathrm{q}_{\mathrm{m}}^{2} \bar{v}, \quad \mathrm{q}_{\mathrm{m}}^{2}=\frac{\mathrm{p}}{\alpha_{\mathrm{m}}}
$$

for which a solution is:

$$
\begin{aligned}
& \bar{\nu}_{m}=A_{m} e^{q_{m}\left(x-b_{m-1}\right)}+B_{m} e^{-q_{m}\left(x-b_{m-1}\right)} \\
& K_{m} \frac{d \bar{\nu}_{m}}{d x}=K_{m} q_{m}\left[A_{m} e^{q_{m}(x-b)}-B_{m} e^{-q_{m}\left(x-b_{m-1}\right)}\right]
\end{aligned}
$$

where $b_{m-1}$ is the distance from $x=0$ (surface of first layer) to the nearest face of the $m$-th layer. Applying the continuity conditions (2) gives the following relations

$$
\begin{aligned}
& \frac{2 A_{m-1}}{\left(1+\sigma_{m-1}\right)}=A_{m} e^{-y_{m-1}}+k_{m-1} B_{m} e^{-y_{m-1}} \\
& \frac{2 B_{m-1}}{\left(1+\sigma_{m-1}\right)}=k_{m-1} A_{m} e^{y_{m-1}}+B_{m} e^{y_{m-1}}
\end{aligned}
$$


where

$$
\begin{aligned}
& \sigma_{m-1}=\frac{k_{m}}{k_{m-1}} \sqrt{\frac{\alpha_{m-1}}{\alpha_{m}}} \\
& k_{m-1}=\frac{1-\sigma_{m-1}}{1+\sigma_{m-1}} \\
& y_{m-1}=\frac{\left(b_{m-1}-b_{m-2}\right) \sqrt{p}}{\sqrt{\alpha_{m-1}}}=\frac{\ell_{m-1} \sqrt{p}}{\sqrt{\alpha_{m-1}}}
\end{aligned}
$$

and $\ell_{m-1}$ is the thickness of the $(m-1)-t h$ layer. This process is continued until the constants $A_{1}$ and $B_{1}$ (pertaining to the layer with face exposed at $x=0$ ) are found in terms of $A_{n}$ and $B_{n}$ (pertaining to the $n$-th layer with face exposed at $\left.x=b_{n}\right)$. At $x=0$, the heat $f$ lux is proportional to the temperature difference between the fluid (air, gas or liquid) and the surface, and is represented by the relationship

$$
-R_{1} K_{1} \frac{d v_{1}}{d x}=f(t)-v_{1}
$$

where $R_{1}$ is the surface film resistance and $f(t)$ is fluid temperature as a function of time. Similarly, the boundary condition at $x=b_{n}$ is

$$
-R_{2} K_{n} \frac{d \nu_{n}}{d x}=\nu_{n}-g(t)
$$

where $R_{2}$ is the surface film resistance and $g(t)$ is a fluid temperature as a function of time. When either $R_{1}$ or $R_{2}$ is zero, the time temperature function represents temperatures at the respective surfaces. The resulting expressions for the transform of the temperatures in layer 1 and layer $n$ are given by 


$$
\bar{v}_{1}=\frac{\bar{f}(p)}{W}\left[P_{1}+Q_{1}+V_{2} \sqrt{p}\left(S_{1}+T_{1}\right)\right]+\frac{H \bar{g}(p)}{W}\left[\sinh x \sqrt{\frac{p}{\alpha_{1}}}+v_{1} \sqrt{P} \cosh x \sqrt{\frac{P}{\alpha_{1}}}\right]
$$

and

$$
\begin{aligned}
\bar{\nu}_{n} & =\frac{G \bar{f}(p)}{W}\left[\sinh \sqrt{\frac{p}{\alpha_{n}}}\left(b_{n}-x\right)+v_{2} \sqrt{P} \cosh \sqrt{\frac{p}{\alpha_{n}}}\left(b_{n}-x\right)\right]+ \\
& +\frac{\bar{g}(p)}{W}\left[P_{2}+Q_{2}+v_{1} \sqrt{p}\left(s_{2}-T_{2}\right)\right]
\end{aligned}
$$

where

$$
\begin{array}{ll}
\mathrm{P}_{1}=\sum \mathrm{J}_{\mathrm{m}} \sinh \sqrt{\mathrm{P}}\left(\mathrm{N}_{\mathrm{m}}-\mathrm{x} / \sqrt{\alpha_{1}}\right) & \mathrm{Q}_{1}=\sum \mathrm{L}_{\mathrm{m}} \sinh \sqrt{\mathrm{P}}\left(\mathrm{E}_{\mathrm{m}}+\mathrm{x} / \sqrt{\alpha_{1}}\right) \\
\mathrm{S}_{1}=\sum \mathrm{J}_{\mathrm{m}} \cosh \sqrt{\mathrm{P}\left(\mathrm{N}_{\mathrm{m}}-\mathrm{x} / \sqrt{\alpha_{1}}\right)} & \mathrm{T}_{1}=\sum \mathrm{L}_{\mathrm{m}} \cosh \sqrt{\mathrm{P}}\left(\mathrm{E}_{\mathrm{m}}+\mathrm{x} / \sqrt{\alpha_{1}}\right) \\
\mathrm{P}_{2}=\sum \mathrm{J}_{\mathrm{m}} \sinh \sqrt{\mathrm{P}}\left(\mathrm{N}_{\mathrm{m}}-\left(\mathrm{b}_{\mathrm{n}}-\mathrm{x}\right) / \sqrt{\alpha_{\mathrm{n}}}\right) & \mathrm{Q}_{2}=\sum \mathrm{L}_{\mathrm{m}} \sinh \sqrt{\mathrm{P}}\left(\mathrm{E}_{\mathrm{m}}-\left(\mathrm{b}_{\mathrm{n}}-\mathrm{x}\right) / \sqrt{\alpha}_{\mathrm{n}}\right) \\
\mathrm{S}_{2}=\sum \mathrm{J}_{\mathrm{m}} \cosh \sqrt{\mathrm{P}}\left(\mathrm{N}_{\mathrm{m}}-\left(\mathrm{b}_{\mathrm{n}}-\mathrm{x}\right) / \sqrt{\alpha}_{\mathrm{n}}\right) & \mathrm{T}_{2}=\sum \mathrm{L}_{\mathrm{m}} \cosh \sqrt{\mathrm{P}}\left(\mathrm{E}_{\mathrm{m}}-\left(\mathrm{b}_{\mathrm{n}}-\mathrm{x}\right) / \sqrt{\alpha}_{\mathrm{n}}\right) \\
\mathrm{P}=\sum \mathrm{J}_{\mathrm{m}} \sinh \sqrt{\mathrm{P}} \mathrm{N}_{\mathrm{m}} & \mathrm{Q}=\sum \mathrm{L}_{\mathrm{m}} \sinh \sqrt{\mathrm{P}} \mathrm{E}_{\mathrm{m}} \\
\mathrm{S}=\sum \mathrm{J}_{\mathrm{m}} \cosh \sqrt{\mathrm{P}} \mathrm{N}_{\mathrm{m}} & \mathrm{T}=\sum \mathrm{L}_{\mathrm{m}} \cosh \sqrt{\mathrm{P}} \mathrm{E}_{\mathrm{m}}
\end{array}
$$

(The above summations are over $m=1,2, \ldots 2^{n-2}$, $n$ being the number of 1ayers.)

$$
\begin{aligned}
& \mathrm{W}=\mathrm{P}+\mathrm{Q}+\mathrm{V}_{1} \mathrm{~V}_{2} \mathrm{p}(\mathrm{P}-\mathrm{Q})+\sqrt{\mathrm{P}}\left[\mathrm{V}_{2}(\mathrm{~S}+\mathrm{T})+\mathrm{V}_{1}(\mathrm{~S}-\mathrm{T})\right] \\
& \mathrm{G}=2^{\mathrm{n}-1} /\left(1+\sigma_{1}\right)\left(1+\sigma_{2}\right) \cdot \cdot\left(1+\sigma_{\mathrm{n}-1}\right), \mathrm{H}=\frac{\mathrm{GK}}{\mathrm{n}} \mathrm{K}_{1} \sqrt{\frac{\alpha_{1}}{\alpha_{\mathrm{n}}}} \\
& \mathrm{N}_{\mathrm{m}}=\sum_{\mathrm{i}=1}^{\mathrm{n}} \mathrm{A}_{\mathrm{i}, \mathrm{m}} \frac{\mathrm{l}_{i}}{\sqrt{\alpha_{1}}}, \quad \mathrm{E}_{\mathrm{m}}=\mathrm{N}_{\mathrm{m}}-\frac{2 \ell_{1}}{\sqrt{\alpha_{1}}}, \mathrm{~A}_{1, \mathrm{~m}}=1 \\
& \mathrm{~V}_{1}=\mathrm{R}_{1} \mathrm{~K}_{1} / \sqrt{\alpha}_{1}, \quad \mathrm{~V}_{2}=\mathrm{R}_{2} \mathrm{~K}_{\mathrm{n}} / \sqrt{\alpha}_{\mathrm{n}}
\end{aligned}
$$

and $\mathrm{J}_{\mathrm{m}}, \mathrm{L}_{\mathrm{m}}$ and $\mathrm{A}_{\mathrm{i}, \mathrm{m}}$ are defined in Table 1 . 
TABLE 1. Definition For $J_{m}, L_{m}$ and $A_{i, m}$

\begin{tabular}{|c|c|c|c|c|c|c|c|c|}
\hline $\mathrm{m}$ & $\mathrm{J}_{\mathrm{m}}$ & $\mathrm{L}_{\mathrm{m}}$ & $\mathrm{A}_{2}, \mathrm{~m}$ & $\mathrm{~A}_{3, \mathrm{~m}}$ & $\mathrm{~A}_{4, \mathrm{~m}}$ & $\mathrm{~A}_{5, \mathrm{~m}}$ & $\mathrm{~A}_{6, \mathrm{~m}}$ & $\mathrm{~A}_{7, \mathrm{~m}}$ \\
\hline 1 & 1 & $\mathrm{k}_{1}$ & 1 & 1 & 1 & 1 & 1 & 1 \\
\hline 2 & $k_{1} k_{2}$ & $\mathrm{k}_{2}$ & -1 & 1 & 1 & 1 & 1 & 1 \\
\hline 3 & $k_{1} k_{3}$ & $\mathrm{k}_{3}$ & -1 & -1 & 1 & 1 & 1 & 1 \\
\hline 4 & $k_{2} k_{3}$ & $k_{1} k_{2} k_{3}$ & 1 & -1 & -1 & 1 & 1 & 1 \\
\hline 5 & $k_{1} k_{4}$ & $k_{4}$ & -1 & -1 & -1 & 1 & 1 & 1 \\
\hline 6 & $\mathrm{k}_{2} \mathrm{k}_{4}$ & $k_{1} k_{2} k_{4}$ & 1 & -1 & -1 & 1 & 1 & 1 \\
\hline 7 & $k_{3} k_{4}$ & $k_{1} k_{3} k_{4}$ & 1 & 1 & -1 & 1 & 1 & 1 \\
\hline 8 & $k_{1} k_{2} k_{3} k_{4}$ & $k_{2} k_{3} k_{4}$ & -1 & 1 & -1 & 1 & 1 & 1 \\
\hline 9 & $k_{4} k_{5}$ & $k_{1} k_{4} k_{5}$ & 1 & 1 & 1 & -1 & 1 & 1 \\
\hline 10 & $k_{3} k_{5}$ & $k_{1} k_{3} k_{5}$ & 1 & 1 & -1 & -1 & 1 & 1 \\
\hline 11 & $\mathrm{k}_{2} \mathrm{k}_{5}$ & $k_{1} k_{2} k_{5}$ & 1 & -1 & -1 & -1 & 1 & 1 \\
\hline 12 & $k_{1} k_{5}$ & $\mathrm{k}_{5}$ & -1 & -1 & -1 & -1 & 1 & 1 \\
\hline 13 & $k_{1} k_{2} k_{3} k_{5}$ & $k_{2} k_{3} k_{5}$ & -1 & 1 & -1 & -1 & 1 & 1 \\
\hline 14 & $k_{1} k_{2} k_{4} k_{5}$ & $k_{2} k_{4} k_{5}$ & -1 & 1 & 1 & -1 & 1 & 1 \\
\hline 15 & $k_{1} k_{3} k_{4} k_{5}$ & $k_{3} k_{4} k_{5}$ & -1 & -1 & 1 & -1 & 1 & 1 \\
\hline 16 & $k_{2} k_{3} k_{4} k_{5}$ & $k_{1} k_{2} k_{3} k_{4} k_{5}$ & 1 & -1 & 1 & -1 & 1 & 1 \\
\hline 17 & $\mathrm{k}_{5} \mathrm{k}_{6}$ & $k_{1} k_{5} k_{6}$ & 1 & 1 & 1 & 1 & -1 & 1 \\
\hline 18 & $k_{4} k_{6}$ & $k_{1} k_{4} k_{6}$ & 1 & 1 & 1 & -1 & -1 & 1 \\
\hline 19 & $k_{3} k_{6}$ & $k_{1} k_{3} k_{6}$ & 1 & 1 & -1 & -1 & -1 & 1 \\
\hline 20 & $k_{2} k_{6}$ & $k_{1} k_{2} k_{6}$ & 1 & -1 & -1 & -1 & -1 & 1 \\
\hline 21 & $k_{1} k_{6}$ & $\mathrm{k}_{6}$ & -1 & -1 & -1 & -1 & -1 & 1 \\
\hline 22 & $k_{1} k_{2} k_{3} k_{6}$ & $k_{2} k_{3} k_{6}$ & -1 & 1 & -1 & -1 & -1 & 1 \\
\hline 23 & $k_{1} k_{2} k_{4} k_{6}$ & $k_{2} k_{4} k_{6}$ & -1 & 1 & 1 & -1 & -1 & 1 \\
\hline 24 & $k_{1} k_{2} k_{5} k_{6}$ & $k_{2} k_{5} k_{6}$ & -1 & 1 & 1 & 1 & -1 & 1 \\
\hline 25 & $k_{1} k_{3} k_{4} k_{6}$ & $k_{3} k_{4} k_{6}$ & -1 & -1 & 1 & -1 & -1 & 1 \\
\hline 26 & $k_{1} k_{3} k_{5} k_{6}$ & $k_{3} k_{5} k_{6}$ & -1 & -1 & 1 & 1 & -1 & 1 \\
\hline 27 & $k_{1} k_{4} k_{5} k_{6}$ & $k_{4} k_{5} k_{6}$ & -1 & -1 & -1 & 1 & -1 & 1 \\
\hline 28 & $k_{2} k_{3} k_{4} k_{6}$ & $k_{1} k_{2} k_{3} k_{4} k_{6}$ & 1 & -1 & 1 & -1 & -1 & 1 \\
\hline 29 & $k_{2} k_{3} k_{5} k_{6}$ & $k_{1} k_{2} k_{3} k_{5} k_{6}$ & 1 & -1 & 1 & 1 & -1 & 1 \\
\hline 30 & $k_{2} k_{4} k_{5} k_{6}$ & $k_{1} k_{2} k_{4} k_{5} k_{6}$ & 1 & -1 & -1 & 1 & -1 & 1 \\
\hline 31 & $k_{3} k_{4} k_{5} k_{6}$ & $k_{1} k_{3} k_{4} k_{5} k_{6}$ & 1 & 1 & -1 & 1 & -1 & 1 \\
\hline 32 & $k_{1} k_{2} k_{3} k_{4} k_{5} k_{6}$ & $k_{2} k_{3} k_{4} k_{5} k_{6}$ & -1 & 1 & -1 & 1 & -1 & 1 \\
\hline
\end{tabular}


The transforms of the heat flux at $x=0$ and at $x=b_{n}$ are found by differentiating (6) and (7) with respect to $x$ and multiplying by minus one and the respective thermal conductivity:

$$
\begin{aligned}
& \overline{\mathrm{F}}_{1}=\frac{\mathrm{K}_{1} \sqrt{\mathrm{p}}}{\mathrm{W} \sqrt{\alpha}_{\mathrm{n}}}\left[\left\{\mathrm{S}-\mathrm{T}+\mathrm{V}_{2} \sqrt{\mathrm{p}}(\mathrm{P}-\mathrm{Q})\right\} \overline{\mathrm{f}}(\mathrm{p})-\mathrm{H} \overline{\mathrm{g}}(\mathrm{p})\right] \\
& \overline{\mathrm{F}}_{\mathrm{n}}=\frac{\mathrm{K}_{\mathrm{n}} \sqrt{\mathrm{p}}}{\mathrm{W} \sqrt{\alpha}_{\mathrm{n}}}\left[\mathrm{G} \overline{\mathrm{f}}(\mathrm{p})-\left\{\mathrm{S}+\mathrm{T}+\mathrm{v}_{1} \sqrt{\mathrm{P}}(\mathrm{P}-\mathrm{Q})\right\} \overline{\mathrm{g}}(\mathrm{p})\right] .
\end{aligned}
$$

The inversion of ( 8 ) and (9) is performed by evaluating the residues at the poles of the denominator $W=0$, where $p=-\beta^{2}$ or $\sqrt{p}=i \beta$, which gives the relationship

$$
\begin{aligned}
\mathrm{W}_{\beta} & =\left(1-\mathrm{V}_{1} \mathrm{~V}_{2} \beta^{2}\right) \sum \mathrm{J}_{\mathrm{m}} \sin \mathrm{N}_{\mathrm{m}} \beta+\left(1+\mathrm{V}_{1} \mathrm{~V}_{2} \beta^{2}\right) \sum \mathrm{L}_{\mathrm{m}} \sin \mathrm{E}_{\mathrm{m}} \beta \\
& +\beta\left[\left(\mathrm{V}_{2}+\mathrm{V}_{1}\right) \sum \mathrm{J}_{\mathrm{m}} \cos \mathrm{N}_{\mathrm{m}} \beta+\left(\mathrm{V}_{2}-\mathrm{V}_{1}\right) \sum \mathrm{L}_{\mathrm{m}} \cos \mathrm{E}_{\mathrm{m}} \beta\right]=0
\end{aligned}
$$

and the differentiation of $W$ with respect to $p$ evaluated at $p=-\beta^{2}$ gives

$$
\begin{aligned}
& U=\left(1-V_{1} V_{2} \beta^{2}\right) \sum J_{m} N_{m} \cos N_{m} \beta+\left(1+V_{1} V_{2} \beta^{2}\right) \sum L_{m} E_{m} \cos E_{m} \beta \\
&+\left(V_{2}+V_{1}\right)\left[\sum J_{m} \cos N_{m} \beta-\beta \sum J_{m} N_{m} \sin N_{m} \beta\right] \\
&+\left(V_{2}-V_{1}\right)\left[\sum L_{m} \cos E_{m} \beta-\beta \sum L_{m} E_{m} \sin E_{m} \beta\right] \\
&-2 \beta V_{1} V_{2}\left[\sum J_{m} \sin N_{m} \beta-\sum L_{m} \sin E_{m} \beta\right] \\
& \text { or } \quad 2 i \beta\left(\frac{d W}{d p}\right)_{p}=. \cdot \beta^{2}=U .
\end{aligned}
$$


The residues at the poles $\mathrm{p}=-\beta^{2}$ are

$$
F_{1 \beta}=-\frac{2 K_{1}}{\sqrt{\alpha_{1}}} \sum \frac{\beta_{i}^{2}}{U_{i}}\left[\bar{f}\left(-\beta_{i}^{2}\right)\left(D_{1}-V_{2} D_{2} \beta\right)-H \bar{g}\left(-\beta_{i}^{2}\right)\right] e^{-\beta_{i}^{2} t}
$$

and

$$
F_{n \beta}=-\frac{2 K_{n}}{\sqrt{\alpha_{n}}} \sum \frac{\beta_{i}^{2}}{U_{i}}\left[G \bar{f}\left(-\beta_{i}^{2}\right)-\left(D_{3}-V_{1} D_{2} \beta\right) \bar{g}\left(-\beta_{i}^{2}\right)\right] e^{-\beta_{i}^{2} t}
$$

where

$$
\begin{aligned}
& D_{1}=\sum\left(J_{m} \cos N_{m} \beta-L_{m} \cos E_{m} \beta\right), D_{2}=\sum\left(J_{m} \cos N_{m} \beta+L_{m} \cos E_{m} \beta\right), \\
& D_{3}=\sum\left(J_{m} \sin N_{m} \beta-L_{m} \sin E_{m} \beta\right) .
\end{aligned}
$$

of particular concern is the evaluation of the first root of (10). This can be done expeditiously by expanding the sines and cosines in their series and considering only the first two terms, in order to obtain an initial estimate of the first root

$$
\begin{aligned}
& W_{\beta} \approx A_{1} \beta-A_{2} \beta^{3}=0 \\
& B_{1}^{2} \approx A_{1} / A_{2}
\end{aligned}
$$

or

with

$$
A_{1}=\sum\left(J_{m} N_{m}+L_{m} E_{m}\right)+\left(V_{1}+V_{2}\right) \sum J_{m}+\left(V_{2}-V_{1}\right) \sum L_{m}
$$

and

$$
\begin{aligned}
A_{2} & =V_{1} V_{2} \sum\left(J_{m} N_{m}-L_{m} E_{m}\right)+\frac{V_{1}+V_{2}}{2} \sum J_{m} N_{m}^{2}+\frac{V_{2}-V_{1}}{2} \sum L_{m} E_{m}^{2} \\
& +\frac{1}{6} \sum\left(J_{m}{ }^{3}+L_{m}{ }^{3}{ }^{3}\right) .
\end{aligned}
$$


Consider the triangular pulse function of Kusuda [1], where

$$
\begin{aligned}
& f(t)=0 \quad \bar{f}(p)=0 \quad t \leq 0 \\
& =t / \delta \\
& =1 / \delta p^{2} \\
& 0<t \leq \delta \\
& =2-t / \delta \\
& =\left(1-2 \mathrm{e}^{-\mathrm{p} \delta}\right) / \delta \mathrm{p}^{2} \\
& \delta<t \leq 2 \delta \\
& =0 \\
& =\left(1-\mathrm{e}^{-\mathrm{p} \delta}\right)^{2} / \delta \mathrm{p}^{2} \\
& t>2 \delta
\end{aligned}
$$

which when substituted for $\bar{f}(p)$ and $\bar{g}(p)$ in (8) and (9) gives double poles at $\mathrm{p}=0$. Following are limits of the necessary functions of (8) and (9) for evaluating the residues at the double poles.

$$
\begin{aligned}
& \operatorname{Lim}_{p \rightarrow 0}\left(\frac{W}{\sqrt{P}}\right)=A_{1}+A_{2} p \\
& \operatorname{Lim}_{p \rightarrow 0} S-T+V_{2} \sqrt{p}(P-Q)=B_{1}+B_{2} P \\
& \operatorname{Lim}_{p \rightarrow 0} S+T+V_{1} \sqrt{p}(P=Q)=C_{1}+C_{2} P
\end{aligned}
$$

$A_{1}$ and $A_{2}$ are defined by (14) and

$$
\begin{aligned}
& \mathrm{B}_{1}=\sum\left(\mathrm{J}_{\mathrm{m}}-\mathrm{L}_{\mathrm{m}}\right), \quad \mathrm{C}_{1}=\sum\left(\mathrm{J}_{\mathrm{m}}+\mathrm{L}_{\mathrm{m}}\right) \\
& \mathrm{B}_{2}=\frac{1}{2} \sum\left(\mathrm{J}_{\mathrm{m}} \mathrm{N}_{\mathrm{m}}^{2}-\mathrm{L}_{\mathrm{m}} \mathrm{E}_{\mathrm{m}}^{2}\right)+\mathrm{V}_{2} \sum\left(\mathrm{J}_{\mathrm{m}} \mathrm{N}_{\mathrm{m}}-\mathrm{L}_{\mathrm{m}} \mathrm{E}_{\mathrm{m}}\right) \\
& \mathrm{C}_{2}=\frac{1}{2} \sum\left(\mathrm{J}_{\mathrm{m}} \mathrm{N}_{\mathrm{m}}^{2}+\mathrm{L}_{\mathrm{m}} \mathrm{E}_{\mathrm{m}}^{2}\right)+\mathrm{V}_{1} \sum\left(\mathrm{J}_{\mathrm{m}} \mathrm{N}_{\mathrm{m}}-\mathrm{L}_{\mathrm{m}} \mathrm{E}_{\mathrm{m}}\right) .
\end{aligned}
$$

For the first term in ( 8 ), the residue for $0<t<\delta$ is

$$
\bar{x}_{t}=\frac{\mathrm{K}_{1}}{\delta \sqrt{\alpha_{1}}}\left[\frac{\mathrm{tB}_{1}}{\mathrm{~A}_{1}}+\frac{\mathrm{A}_{1} \mathrm{~B}_{2}-\mathrm{A}_{2} \mathrm{~B}_{1}}{\mathrm{~A}_{1}^{2}}\right]
$$


for the last term in (9), the residue is

$$
\overline{\mathrm{z}}_{\mathrm{t}}=\frac{\mathrm{K}_{\mathrm{n}}}{\delta \sqrt{\alpha}_{\mathrm{n}}}\left[\frac{\mathrm{tC}{ }_{1}}{\mathrm{~A}_{1}}+\frac{\mathrm{A}_{1} \mathrm{C}_{2}-\mathrm{A}_{2} \mathrm{C}_{1}}{\mathrm{~A}_{1}^{2}}\right]
$$

and for the first term in (9) and the last term in (8), the residue is

$$
\bar{Y}_{t}=\frac{K_{n} G}{\delta \sqrt{\alpha_{n}}}\left[\frac{t}{A_{1}}-\frac{A_{2}}{A_{1}^{2}}\right]
$$

where

$$
\frac{\mathrm{K}_{1} \mathrm{~B}_{1}}{\mathrm{~A}_{1} \sqrt{\alpha_{1}}}=\frac{\mathrm{K}_{\mathrm{n}} \mathrm{C}_{1}}{\mathrm{~A}_{1} \sqrt{\alpha_{\mathrm{\alpha}}}}=\frac{\mathrm{K}_{\mathrm{n}} \mathrm{G}}{\mathrm{A}_{1} \sqrt{\alpha_{n}}}=\frac{1}{\mathrm{R}}
$$

and $R$ is the total thermal resistance of the $n$-layers $p l u s R_{1}$ and $R_{2}$.

The response factors $\mathrm{X}_{1}, \mathrm{Y}_{1}$ and $\mathrm{Z}_{1}$ evaluated at $\mathrm{t}=\delta$, become

$$
\begin{aligned}
& \mathrm{x}_{1}=\overline{\mathrm{x}}_{\delta}-\frac{\mathrm{K}_{1}}{\sqrt{\alpha}_{1}} \sum\left(\mathrm{D}_{1}-\mathrm{v}_{2} \mathrm{D}_{2} \beta_{i}\right) \psi_{i} \\
& \mathrm{Y}_{1}=\overline{\mathrm{Y}}_{\delta}-\frac{\mathrm{K}_{\mathrm{n}} \mathrm{G}}{\sqrt{\alpha}} \sum \psi_{\mathrm{n}} \\
& \mathrm{z}_{1}=\overline{\mathrm{z}}_{\delta}-\frac{\mathrm{K}_{\mathrm{n}}}{\bar{\alpha}_{\mathrm{n}}} \sum\left(\mathrm{D}_{3}-\mathrm{v}_{1} \mathrm{D}_{2} \beta_{i}\right) \psi_{i}
\end{aligned}
$$

where

$$
\psi_{i}=\frac{2}{\delta} \frac{e^{-\beta_{i}^{2}}}{\beta_{i}^{2 U_{i}}} .
$$


For $\mathrm{X}_{2}, \mathrm{Y}_{2}$ and $\mathrm{Z}_{2}$ evaluated at $\mathrm{t}=2 \delta$,

$$
\begin{aligned}
& x_{2}=\frac{1}{R}-\bar{x}_{\delta}-\frac{K_{1}}{\sqrt{\alpha_{1}}} \sum\left(D_{1}-V_{2} D_{2} \beta_{i}\right) \psi_{i}\left(e^{-\beta_{i}^{2} \delta}-2\right) \\
& \mathrm{Y}_{2}=\frac{1}{\mathrm{R}}-\overline{\mathrm{Y}}_{\delta}-\frac{\mathrm{K}_{\mathrm{n}} \mathrm{G}}{\sqrt{\alpha_{\mathrm{n}}}} \sum \psi_{i}\left(\mathrm{e}^{-\beta_{i}^{2}}-2\right) \\
& z_{2}=\frac{1}{R}-\bar{z}_{\delta}-\frac{K_{n}}{\sqrt{\alpha_{n}}} \sum\left(D_{3}-V_{1} D_{2} \beta_{i}\right) \psi_{i}\left(e^{-\beta_{i}^{2} \delta}-2\right),
\end{aligned}
$$

and for $t>2 \delta$,

$$
x_{j}=-\frac{K_{1}}{\sqrt{\alpha_{1}}} \sum\left(D_{1}-V_{2} D_{2} \beta_{i}\right) \psi_{i}\left(1-e^{-\beta_{i}^{2} \delta}\right)^{2} e^{-(j-3) \beta_{i}^{2} \delta}
$$

For larger values of $j$, the response factors decrease with increase in j by a common ratio - i.e., for $\mathrm{N}$ sufficiently large,

$$
\overline{C R}=e^{-\beta_{1}^{2} \delta}=\frac{X_{j}+1}{X_{j}}=\frac{Y_{j}+1}{Y_{j}}=\frac{Z_{j}+1}{Z_{j}}
$$

for all $j \geq N$, where $\beta_{1}$ is the first root of (10). Thus for $j$ greater than $\mathrm{N}$, the response factors can be computed by the relationship

$$
x_{j+1}=x_{j} \cdot \overline{C R}
$$

The temperatures $f(t)$ and $g(t)$ may be constructed from a series of triangular pulse functions (15), overlapping in time by an amount $\delta$. By the principle of superposition, the heat flux at time $\tau$ is determined from the sum of the products of the response factors and the temperatures from the present time to preceding time intervals of duration $\delta$. The heat flow at time $t=\tau$ and 
at the $x=0$ face is then

$$
F_{1, \tau}=\sum_{i=1}\left(X_{i} V_{1, \tau-i+1}-Y_{i} V_{n, \tau-i+1}\right)
$$

and the heat $\mathrm{flux}$ at $\mathrm{x}=\mathrm{b}_{\mathrm{n}}$ is

$$
F_{n, \tau}=\sum_{i=1}\left(Y_{i} V_{1, \tau-i+1}-z_{i} V_{n, \tau-i+1}\right)
$$

where $\mathrm{V}$ is the temperature potential in relation to a fixed datum plane temperature, which is referenced to time, $t=\tau, \tau-1, \tau-2$, etc.

For certain types of constructions, the number of required response factors can become quite large to give a reasonable accuracy to the heat fluxes of (23) and (24). Conduction transfer functions can reduce this number considerably and are defined from the relationship, $F_{1, \tau}-C R_{1, \tau-1}$ of (23) and similarly from (24). The conduction transfer functions are then defined as follows:

$$
\begin{array}{lll}
X_{1}^{\prime}=X_{1} & Y_{1}^{\prime}=Y_{1} & z_{1}^{\prime}=z_{1} \\
X_{j}^{\prime}=X_{j}-\overline{C R} X_{j-1} & Y_{j}^{\prime}=Y_{j}-\overline{C R} \quad Y_{j-1} & z_{j}^{\prime}=z_{j}-\overline{C R} \quad z_{j-1}
\end{array}
$$

Using these functions, the heat flux at $t=\tau$ and $x=0$ becomes

$$
F_{1, \tau}=\overline{C R} \cdot F_{1, \tau-1}+\sum_{j=1}\left(X_{j}^{\prime} V_{1, \tau-j+1}-Y_{j}^{\prime} V_{n, \tau-j+1}\right)
$$

From (21) and (25), it can be seen that the conduction transfer function's are numerically very small numbers as $\mathrm{j}$ approaches $\mathrm{N}$, and the number of functions needed for computation purposes is considerably reduced. However, 
initially it is necessary to know the value of $F_{1, \tau-1}$. This must be determined from several iterations over the past temperature history of $v_{1}$ and $v_{n}$.

\section{RESPONSE FACTORS}

Using the algorithms of the previous section, the response factors of equations (19), (20), and (21) are calculated from the computer program found in Appendix A. To show time savings in response-factor calculations, identical multi-1ayer constructions were input into both the program of Kusuda [1] and the program of Appendix A. Six multi-layer constructions are shown in Table 2, and the computation times for the two programs are shown in Table 3. As can be seen, considerable time saving is available from the program of Appendix A.

In the example of Table 2, there is an evident lack of enclosed air spaces in the building construction. Kusuda [2] assumed only a purely thermal resistance effect of air spaces during dynamic temperature changes. It is the supposition of the author that both the air space thickness and the heat capacity of the air should be considered for heat transfer calculations. From literature values, the thermal diffusivity of dry air varies from $0.639 \mathrm{ft}^{2} / \mathrm{h}$ at $0{ }^{\circ} \mathrm{F}$ to $.977 \mathrm{ft}^{2} / \mathrm{h}$ at $120^{\circ} \mathrm{F}$, and these values are reduced somewhat by the presence of water vapor. For the program of Appendix A, the thermal diffusivity of air in air spaces is assumed to be $0.75 \mathrm{ft}^{2} / \mathrm{h}$, the air space thickness is assumed to be one inch if not specified by the input card, and the thermal resistance is as defined for steady-state air-space values. 
Table 2. Multi-Layer Constructions

\begin{tabular}{ccccc} 
& Layer & Thermal & & Specific \\
Layer & Thickness & Conductivity & Densitsy & Heat \\
Description & $\mathrm{ft}$ & $\mathrm{Btu} / \mathrm{h} \mathrm{ft} \mathrm{F}$ & $1 \mathrm{~b} / \mathrm{ft}$ & $\mathrm{Btu} / \mathrm{b} \mathrm{F}$ \\
\hline
\end{tabular}

Case 1 Two Layers

1 1-IN MINERAL FIBERBOARD

2 4-IN LIGHT-WEIGHT CONCRETE

Case 2 Three Layers

1 5/8-IN PLASTER BOARD

$23-1 / 2$ IN BATT INSULATION

3 3/4-IN WOOD SIDING

Case 3 Four Layers

1 1/2-IN PLASTER BOARD

3/4-IN POLYSTYRENE INSULATION

4-IN COMMON BRICK

4-IN FACE BRICK

Case 4 Five Layers

$11 / 2-I N$ PLASTER BOARD

2 1-IN BATT INSULATION

3 4-IN L.W. CONCRETE

$43 / 4-I N$ BOARD INSULATION

$5 \quad 1-I N$ STUCCO

Case 5 Six Layers

$13 / 4-I N$ ACOUSTIC TILE

2 4-IN HEAVY WEIGHT CONCRETE

3 2-IN ROOF INSULATION

4 2-IN H.W. CONCRETE

$53 / 8-I N$ FELT

$61 / 2-I N$ SLAG

Case 6 Seven Layers

2

1/2-IN PLASTER BOARD

.0625

1 -IN BATT INSULATION

1/2-IN PLYWOOD

3-IN H.W. CONCRETE

1/2-IN PLYWOOD

3/4-IN BOARD INSULATION

1 -IN STUCCO
.0417

.0417

.3333

.1667

.1667

.0313

.0417

0.833

.0521

2917

.0625

.0417

.0833

.3333

.0833

.0833

.0417

.2500

.0417

.0625

.0833
.035

.100

.094

.026

.800

.094

.094

.417

.750

.094

.026

.100

.017

.400

.035

1.000

.025

1.000

.110

.830

.094

.026

.067

1.000

.067

.017

.400
23.0

40.0

.140

.200

50.0

2.0

36.0

.260

.220

.280

50.0

50.0

120.0

130.0

.260

.260

.190

.190

50.0

.260

2.0

.220

40.0

.200

2.2

.290

116.0

.200
30.0

140.0

5.7

140.0

70.0

55.0

50.0

2.0

34.0

140.0

34.0

2.2

116.0
.200

.200

.200

.200

.400

.400 
Table 3. Execution Time for Computation of Response Factors, Seconds

\section{Kusuda [1] Appendix A Time Savings}

Two layers

Three layers

Four layers

Five layers

Six layers

Seven layers
2.037

8.885

1.902

3.018

1.609

9.786
.187

.174

.378

.625

.846

1.681
1.850

8.711

1.524

2.393

.763

8.105

Table 4. Heat Flux at Inside Surface of Wood Frame Construction with Air Space, Btu/h $\mathrm{ft}^{2}$

\section{Time (hr) No heat capacity}

$\begin{array}{lr}1 & 1.742 \\ 2 & 1.262 \\ 3 & 1.359 \\ 4 & 1.548 \\ 5 & 1.707 \\ 6 & .964 \\ 7 & -1.966 \\ 8 & -6.113 \\ 9 & -10.410 \\ 10 & -14.248 \\ 11 & -17.427 \\ 12 & -19.720 \\ 13 & -20.908 \\ 14 & -20.827 \\ 15 & -19.497 \\ 16 & -17.038 \\ 17 & -13.592 \\ 18 & -9.416 \\ 19 & -4.960 \\ 20 & -1.785 \\ 21 & - \\ 22 & -746 \\ 23 & +.214 \\ 24 & .239 \\ 17 & .680\end{array}$

$31 / 2^{\prime \prime}$ air space

1.021

1. 242

1. 342

1.525

1.691

1.109

- 1.598

- 5.684

$-9.924$

$-13.809$

$-17.065$

$-19.463$

$-20.783$

$-20.849$

$-19.660$

$-17.334$

$-13.996$

$-9.908$

$-5.459$

$-2.088$

- .870

$-\quad .281$

$+.185$

.628
$51 / 2^{\prime \prime}$ air space

\section{.954}

1. 203

1. 319

1.494

1.666

1.233

$-1.154$

- 5.024

$-9.214$

$-13.144$

$-16.501$

$-19.042$

$-20.544$

$-20.822$

$-19.846$

$-17.718$

$-14.552$

$-10.599$

- 6.201

- 2.639

- 1.128

$-\quad .414$

$+.093$

.547 
The introduction of these changes does alter the response factors and heat flux amplitudes in response to external temperature variations. Table 4 gives heat flux values at the inside surface for a wood-frame construction, with no heat capacity [2], and $31 / 2$ and $51 / 2$ inch air spaces. The external temperature variation is taken from Figure 1.

\section{VERIFICATION OF RESPONSE FACTORS}

Response factors as defined in this paper are the result of an analytical formulation which employs a past time history of overlapping pulses for the temperatures at or adjacent to surfaces of composite solids to determine the heat flux or temperature at present time. A linear variation in temperature over the time period, (usually one hour) is assumed. The ability of response factors to give accurate values for heat flux has been questioned. For this reason, it is appropriate to compare the numerical results from the response-factor calculation with those from another analytical calculation.

Analytical solutions can be found from equations (6) and (7), where the temperature-time functions can be defined by the trigonometric series, $f(t)=\Sigma\left(A_{n} \cos W_{n} t+B_{n} \sin W_{n} t\right) ; \quad \bar{f}(p)=\Sigma \frac{A_{n} P+B_{n} W_{n}}{p^{2}+W_{n}^{2}}$

and

$g(t)=C_{0}+\Sigma\left(C_{n} \cos W_{n} t+D_{n} \sin W_{n} t\right) ; \bar{g}(p)=\frac{C_{0}}{p}+\sum \frac{C_{n} p+D_{n} W_{n}}{p^{2}+W_{n}^{2}}$ 


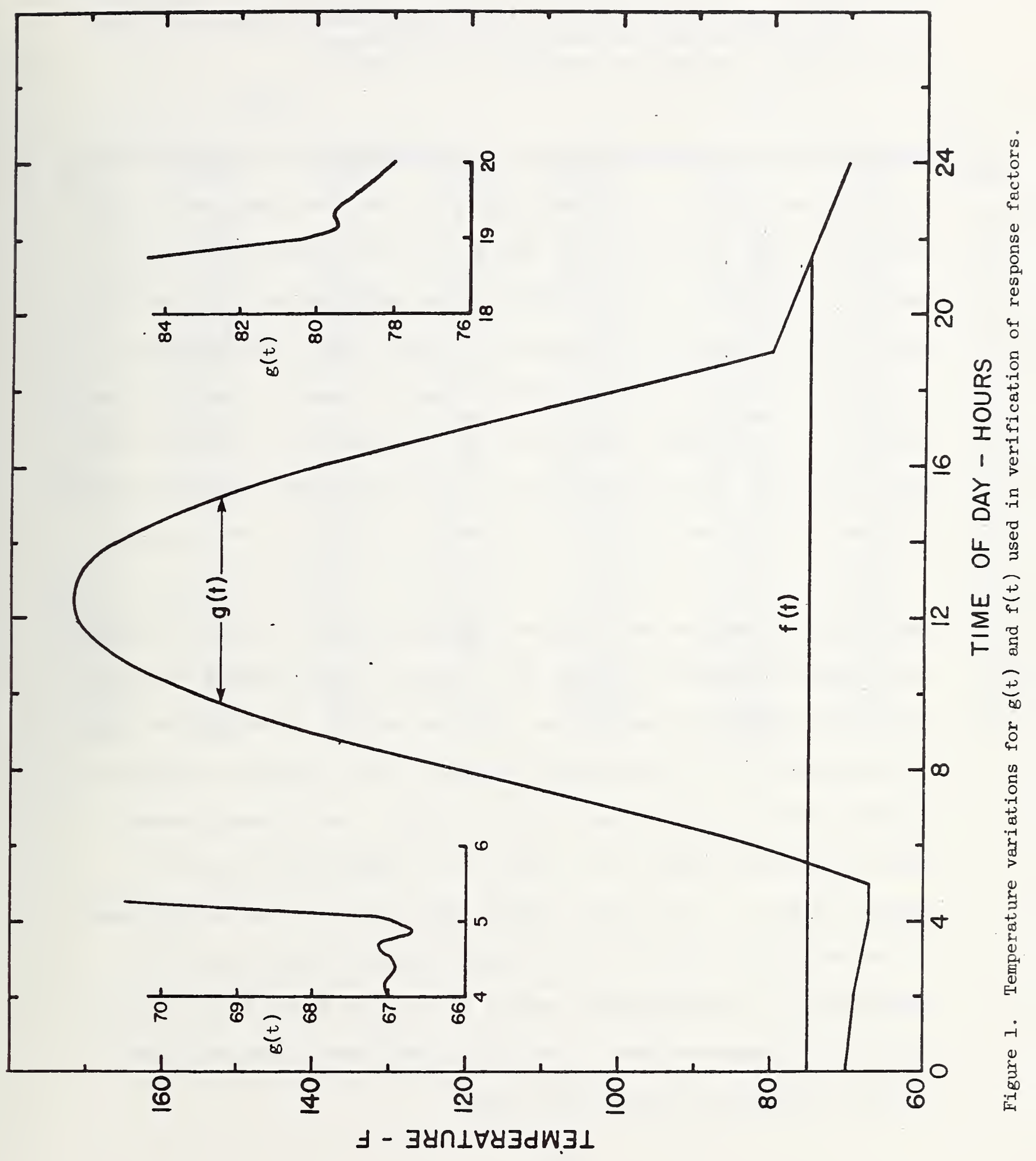


Considering only the steady periodic condition, the residues at the poles at $p=0$ and $p= \pm i w_{n} c$ an be found for the surface temperatures. Heat flow at the surfaces can then be obtained from (4) and (5).

The six examples of Table 2 were used in determination of heat flux for both the response factor and analytical solution. The temperature variation, $g(t)$ shown in Figure 1 was used for the test cases, with $f(t)=0$ and $R_{1}=0.68$ and $R_{2}=.333 \mathrm{hft}{ }^{2} \mathrm{~F} / \mathrm{Btu}$. The coefficients $C_{0}, C_{n}$ and $D_{n}$ were determined from 96 points where there was linear interpolation between the hourly points. This was necessary to assure a nearly linear variation in temperature between the hourly points for the function $g(t)$. When coefficents were determined for 24 and 48 points the agreement between the heat flux for the analytical and response factor was not as good.

Heat flux was computed both from the response factors [(23) and (24)] and the conduction transfer function (26). For all cases examined the heat flux at the inside surface was less than one percent different from the values computed for the analytical solution. At the outside surface, the agreement was not as good, particularly around 5 and 19 hours, where there are sudden changes in the slope of the temperature curve (as shown on Figure 1). The detail figures show that the function $g(t)$ used in the analytical solution varies considerably from the linear form required by the response-factor method in the time period 4 to 5 and 19 to 20. It is expected that if more points were used, there would be a better agreement at the outside surface. 
Table 5. Comparison of Heat Flux Values Calculated from

Response-Factor and Analytical Methods Btu/h $\mathrm{ft}^{2}$

Case 2 .

Outside Surface

Resp.

1.128
.487
1.177
1.268
.652
9.247

$-15.479$

$-16.531$

$-16.683$

$-15.951$

$-14.261$

$-11.537$

- 7.701

- 3.379

.709

5.175

8.621

12.274

11.223

1.296

1.226

1.366

1.520

1.676
Ana1.

1.103

.503

1.152

1.195

.304

$-9.338$

$-15.366$

$-16.412$

$-16.552$

$-15.807$

$-14.108$

$-11.379$

$-7.565$

- 3.286

.783

5.183

8.604

12.076

10.820

1.332

1. 242

1.371

1.517

1.648
Inside Surface

Resp.

.358

.442

.479

.542

.604

.430

$-.489$

$-1.933$

$-3.456$

$-4.861$

$-6.047$

$-6.930$

$-7.432$

$-7.488$

$-7.091$

$-6.284$

$-5.110$

$-3.661$

$-2.065$

$-.811$

$-.333$

$-.113$

.055

.214

Case 3 .

\begin{tabular}{ll} 
Outside & Surface \\
\hline Resp. & Anal.
\end{tabular}

39.450

34.607

32.679

30.798

27.171

- 2.856

- 38.739

$-65.508$

- 84.931

- 96.946

$-101.138$

- 96.975

- 83.896

- 63.289

- 37.984

- 8.151

21.992

53.149

71.912

58.711

52.360

48.294

45.399

43.178
39.437
34.609

32.668

30.768

27.036

2.920
$-\quad 38.726$

- 38.726

- 65.481

- 84.961

- 96.894

$-101.076$

$-96.904$

- 83.828

- 63.233

- 37.933

- 8.124

22.007

53.093

71.763

58.703

52.354

48.290

45.394

43.164
Inside Surface

Resp. Anal.

$-5.468$

$-5.468$

$-4.867$

$-4.295$

$-3.763$

$-3.271$

$-2.816$

$-2.408$

$-2.110$

$-2.012$

$-2.170$

$-2.590$

$-3.238$

$-4.058$

$-4.978$

$-5.916$

$-6.786$

$-7.509$

$-8.015$

$-8.254$

$-8.195$

$-7.857$

$-7.332$

$-6.722$

$-6.901$

$-4.866$

$-4.295$

$-3.763$

$-3.270$

$-2.816$

$-2.408$

$-2.109$

$-2.011$

$-2.169$

$-2.589$

$-3.237$

$-4.057$

$-4.978$

$-5.916$

$-6.787$

$-7.510$

$-8.016$

$-8.255$

$-8.197$

$-7.858$

$-7.332$

$-6.722$

$-6.091$ 
Comparison of calculated heat flux values from the analytical and response. factor methods is shown in Table 5 for Cases 2 and 3.

\section{CONCLUSIONS}

Formulas for calculating thermal response factors for plane multi-layer constructions have been developed as given by equations (19), (20), and (21). A computer program to obtain response factors based on these formulas is found in the Appendix. A comparison was made of the time for computation of response factors between the matrix algebra method of Kusuda [1] and the method given in this paper. A considerable saving in computation time is realized by the methods of this paper.

Presently, the response-factor calculations for constructions with air spaces assume only a purely thermal resistance effect of air spaces during dynamic temperature variations [2]. The heat transfer across an air space involves the nature of the bounding surfaces, the intervening air, orientation of the space and the direction of heat flow: and hence the three modes of heat transfer--radiation, convection, and conduction-influence heat flow in an air space. It would be impractical to simulate the three modes of heat transfer for constantly changing air space surface temperatures, but it is felt that a reasonable approximation should include both the heat capacity and air space thicknessfor dynamic heat transfer calculations. These were included in the computer program of the Appendix. The introduction of these changes gives different values for the response factors and resulting heat-flux amplitudes. 
Response factors are analytical formulations from the partial differential equations for heat conduction. When properly applied, the responsefactor method gives correct values for temperature and heat flow for conduction heat transfer problems.

6. REFERENCES

1. T. Kusuda, Thermal Response Factors for Multi-Layer Structures of Various Conduction Systems, ASHRAE Transactions, Vol. 75, 1969.

2. T. Kusuda, NBSLD, The Computer Program for Heating and Cooling Loads in Buildings, NBS-BSS-69, U.S. Government Printing Office, Wash., D.C. 20402 .

7. CONVERSION FACTORS TO METRIC (S.I.) UNITS

Physical Quantity

Length

Area

Temperature

Density

Thermal Conductivity

Thermal Resistance

Thermal Diffusivity

Heat Flux

Specific Heat

Time

\section{To Convert}

$\frac{\mathrm{Ft}}{\mathrm{ft}} \mathrm{t}^{2}$

F

$1 \mathrm{bm} / \mathrm{ft}^{3}$

Btu/h ftF

h $\mathrm{ft}^{2} \mathrm{~F} / \mathrm{Btu}$

$f t^{2} / h$

Btu/h $\mathrm{ft}^{2}$

Btu/1bmF

h

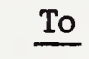

m

$\mathrm{m}^{2}$

C

$\mathrm{kg} / \mathrm{m}^{3}$

$\mathrm{W} / \mathrm{mK}$

$\mathrm{m}^{2} \mathrm{~K} / \mathrm{W}$

$\mathrm{m}^{2} / \mathrm{s}$

$\mathrm{W} / \mathrm{m}^{2}$

j/kgK

s
Multiply By

$3.0480 \mathrm{E}-1$

$9.2903 \mathrm{E}-2$

$(F-32) / 1.8$

$1.6018 \mathrm{E}+1$

$1.7296 \mathrm{E}+\mathrm{O}$

$1.7623 \mathrm{E}-1$

$2.9900 \mathrm{E}-3$

$3.1525 \mathrm{E}+\mathrm{O}$

$4.1840 E+3$

$3.6000 \mathrm{E}+3$ 
APPENDIX A

Appendix A gives a Fortran listing of computations for the response

factors and includes input of data identical to that of Kusuda [1]. 


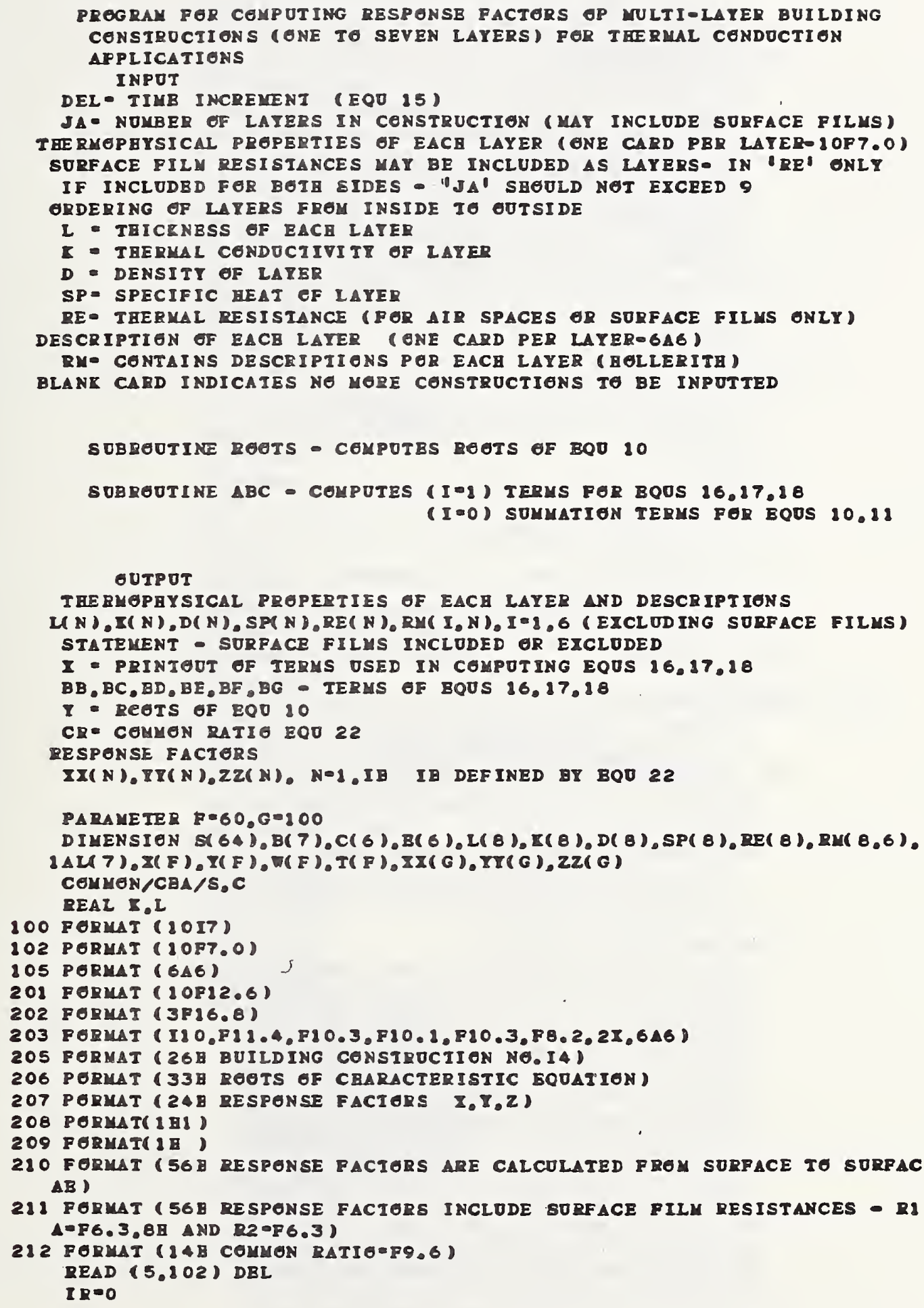




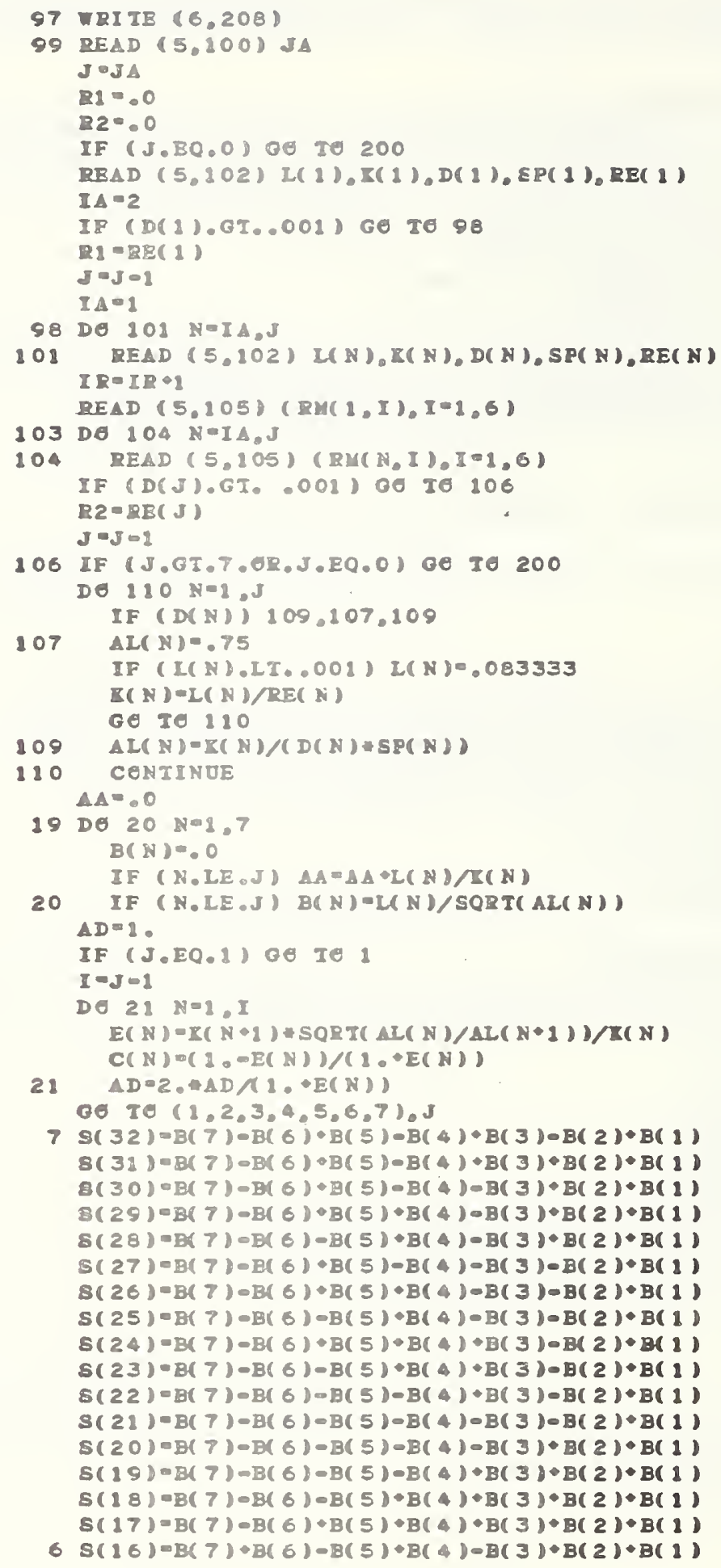


$B(15)-B(7)-B(6)-B(5) \bullet B(4)-B(3)-B(2) \cdot B(1)$ $S(14)-B(7) \cdot B(6)-B(5) \cdot B(4) \cdot B(3)-B(2) \bullet B(1)$ $B(13)=B(7) \cdot B(6)-B(5)-B(4) \bullet B(3)-B(2) \bullet B(1)$ $S(12)=B(7) \cdot B(6) \circ B(5)-B(4) \circ B(3) \circ B(2) \bullet B(1)$ $S(21)=B(7) \bullet B(6)-B(5)-B(4)-B(3) \bullet B(2) \bullet B(1)$ $B(10)=B(7) \bullet B(6)-B(5) \circ B(4) \bullet B(3) \bullet B(2) \bullet B(1)$ S( 9$) \bullet B(7) \circ B(6)-B(E) \bullet B(4) \bullet B(3) \bullet B(2) \bullet B(1)$

5 S( 8$)=B(7) \bullet B(6) \bullet B(5)-B(4) * B(3) \circ B(2) * B(1)$ s( 7$)=B(7) \bullet B(6) \bullet B(5) \circ B(4) \bullet B(3) \bullet B(2) \bullet B(1)$ B( 6$)-B(7) \bullet B(6) \bullet B(5)-B(4)-B(3) \bullet B(2) \bullet B(1)$ $S(5)-B(7) \bullet B(6) \bullet B(5)-B(4)-B(3)-B(2) \bullet B(1)$

4 S( 4$)=B(7) \bullet B(6) \bullet B(5) \bullet B(4) \circ B(3) \bullet B(2) \bullet B(1)$ S( 3$)-B(7) \cdot B(6) \bullet B(5) \bullet B(4)-B(3)-B(2) \bullet B(1)$

$3 \mathrm{~S}(2)-\mathrm{B}(7) \bullet \mathrm{B}(6) \bullet \mathrm{B}(5) \cdot \mathrm{B}(4) \cdot \mathrm{B}(3) \circ \mathrm{B}(2) \bullet \mathrm{B}(1)$

$28(1) \bullet B(7) \bullet B(6) \bullet B(5) \bullet B(4) \bullet B(3) \bullet B(2) \bullet B(1)$ 00 I0 9

$1 \mathrm{~S}(\mathrm{i})=\mathrm{B}(\mathrm{I})$

9 De $8 \quad \mathrm{~N}=1.32$

$I=\mathrm{N} * 32$

a $\quad S(I)=S(N)+2 \cdot B(I)$ $\triangle B=\mathbf{R}(1) / S Q R T(A L(1))$ $\triangle C=E(J) / S O R T(A L(J))$ $\nabla 1=R 1 * \Delta B$ $\nabla 2 \cdot 92 \div A C$ $I \bullet 1$

CAII ABC(CA, I,J,I)

$C A=\nabla 1 \div \nabla 2$ $\mathrm{CB}=\nabla 2 \cdot \nabla 1$ $C C=\nabla 2-\nabla 1$ $B A=z(2) \cdot z(6) \bullet C B * x(1) \cdot C \operatorname{ce} x(5)$ $B B=\Delta B=(I($ \& $)=I(5)) / B A$ $B C=\Delta C=(I(1) \cdot I(5)) / B A$ $B D=\triangle C=\triangle D / B A$

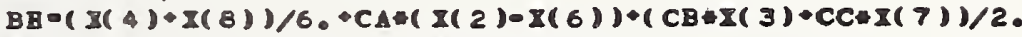
$B I \cdot(I(3)-I(7)) / 2 \cdot \nabla 2 *(X(2)-I(6))$

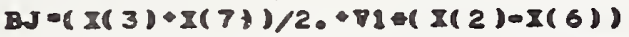

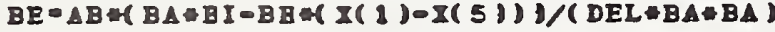

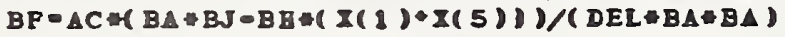
$B G=-A C \triangle D=B H /(D E L=B A B A$ )

I( 1$)=\operatorname{SQRT}(\mathrm{B} \triangle / \mathrm{BH})$

CALI ReGTS( $\triangle B, \triangle C, A I, \nabla 1, \nabla 2, D E L, I, I, I, V, J, U)$

$Z I(1) \bullet B B \bullet B E$

$Z Z(1)-B C \bullet B F$

$I I(\&)-B D \bullet B G$

$I I(2)=-B E$

$Z 2(2)=-B F$

$I X(2)=-B G$

Do $50 \mathrm{~N}=1 . \mathrm{M}$

$I X(\&)=I I(1)-I(N)$

$2 Z(1)=Z Z(1)-v(N)$

$I T(1)=I I(1)-T(N)$

CA $-E I P(-D E L-I(N)=2)-2$.

$X X(2)=I X(2)-I(N)=C A$

$z 2(2)=2 Z(2)-\pi(N)=C A$

50

$I Y(2)=Y \Psi(2)-T(N)=C A$

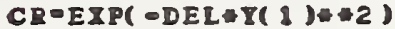

DE $56 \quad I=3, G$

IX( I) $=0.0$

II I I $) 0.0$

$22(I) 0.0$ 


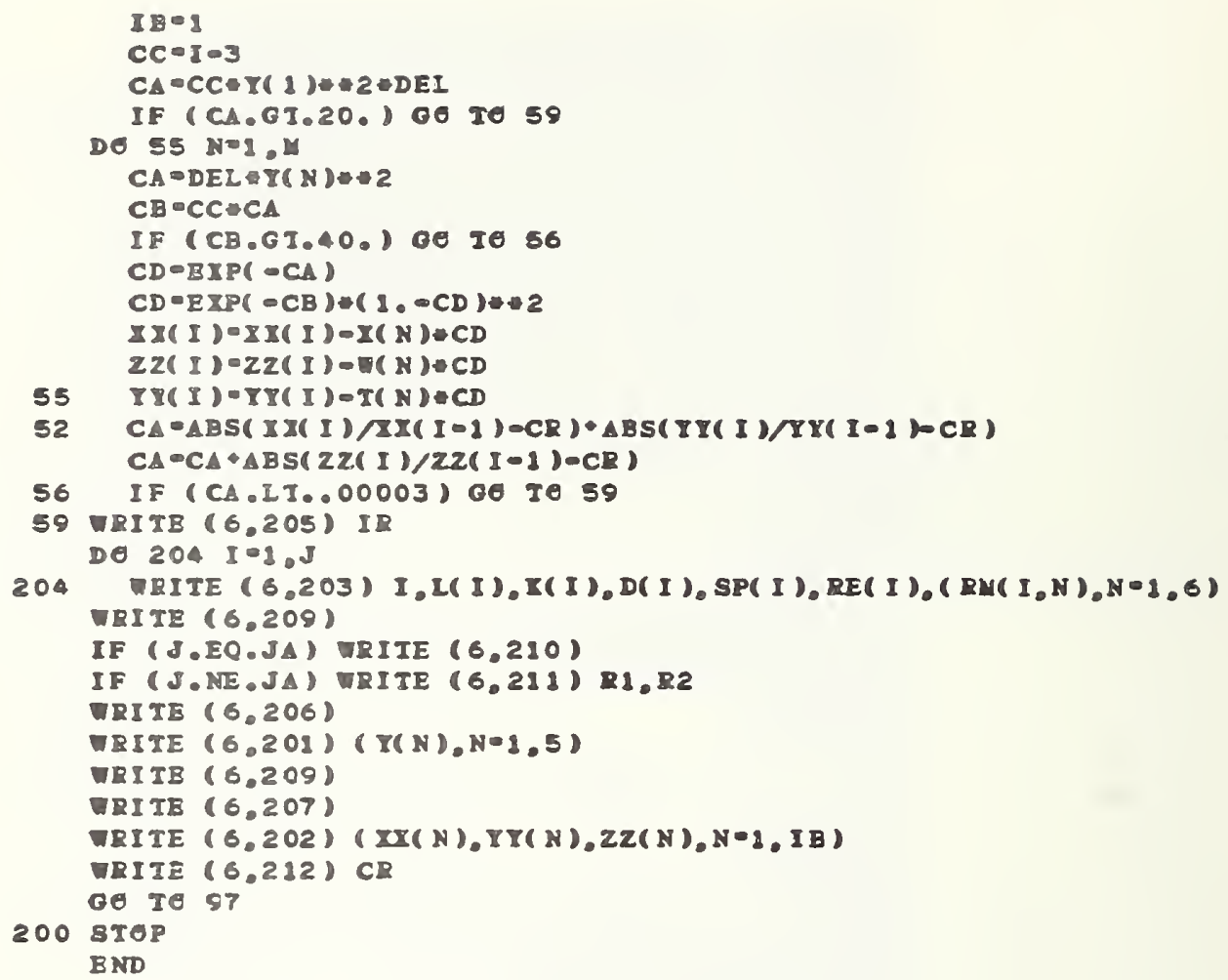




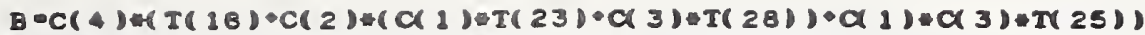
$\Delta \cdot A \cdot B \cdot C(3) *(I(15) \cdot C(1) * C(2) * T(22)) \cdot C(1) * T(21)$

$\boldsymbol{I}=\mathbf{T} \cdot \mathrm{C}(6)=\mathrm{A}$

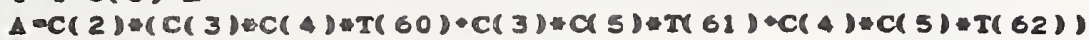

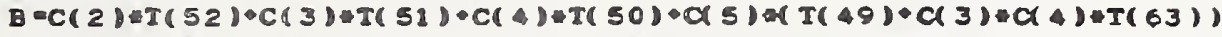

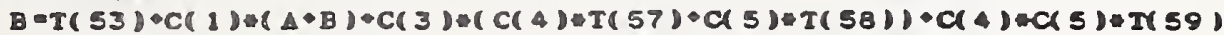

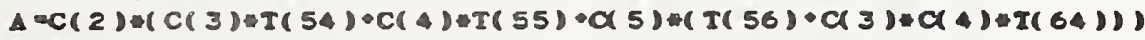
$\nabla=T \cdot C(\sigma) *(\Delta * B)$

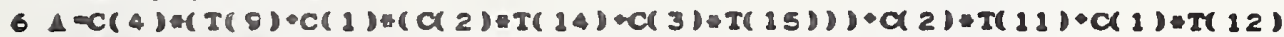

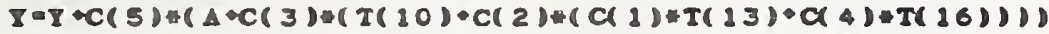

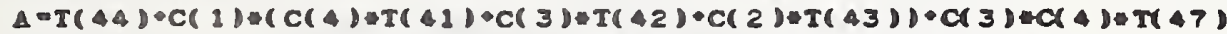

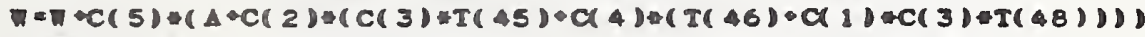

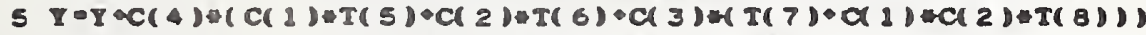

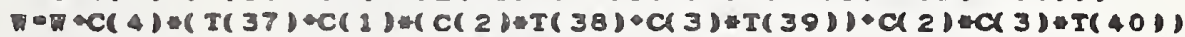

$4 T=T \cdot C(3) *(C(1) \bullet T(3) \cdot C(2) \div I(4))$

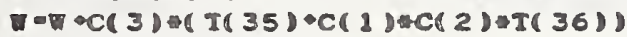

$3 \quad \mathrm{I} \cdot \mathrm{I} \bullet \mathrm{C}(1) * \mathrm{C}(2) \div \mathrm{I}(\mathrm{2})$

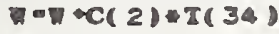

$2 \mathrm{~T} \nabla \bullet \mathrm{T}(\mathrm{I})$

$\left.n=\pi \cdot \mathrm{C}^{2} 1\right) \mathrm{I}(33)$

$z(I) \bullet \mathbb{Z}$

$\mathbf{Z}(\mathbf{I} \bullet 4) \cdot \frac{1}{20}$

$16 \mathrm{I} \cdot \mathrm{I} \bullet \mathrm{g}$

IF (I.BQ.1) GO IO 22

IF $\left(I_{. L E .4)}\right.$ Ge IO 12

RET ORN

$1 \mathrm{Z}(\mathrm{I}) \cdot \mathrm{T}(\mathrm{d})$

$z(I * 4)=0$

CO IO 16

20 DE $28 \mathrm{~N}=1.64$

21 I $N)=1$.

$0020 \cdot 15$

22 DO $23 \mathrm{~N}=1.64$

$23 T(N)=T(N)=S(N)$

IF ( I.LE.4) OO TO 25

RETORN

BND

SUBROUTINE ROCTS( $\triangle B, \triangle C, \triangle D, \nabla 1, V 2, D E L, B, Z, P, R, J, U)$

DIMENSIEN B( 2 ), Z( 1$), P(1), R(1), T(B)$

$I \circ 0$

$\nabla=\nabla 1-\nabla 2$

$0=\operatorname{V} 2 \cdot \nabla \&$

$\mathrm{E}=\mathrm{V} 2-\mathrm{VI}$

$8=2$.

0.02

$M \circ 1$

I 00

$\Delta=.005$

CALI $\triangle B C(A, I, J, I)$

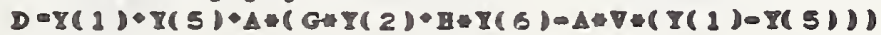

$\mathbf{z}=\mathbf{z}(1)$

$B \cdot .15 \cdot 8$

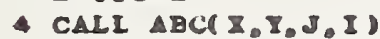

$A \cdot I(1) \cdot I(5) \cdot I *(G) Y(2) \cdot B+T(6) 0 I * V *(Y(1)-I(5)))$

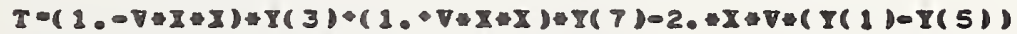

IF ( $\triangle B S(\Delta), L T \cdot 1, E-6)$ oO 207 
IF (I.GT.2) CO IO 6

INCREMENIING TO OBIAIN FIRSI ZBBO - AND APPROIIMTE POE OTHERS IF ( $\triangle A D) 5.5 .6$

$S I=I=E$

$E \cdot E / 2$.

IF (M.BO.1) OO TO

$z \cdot I \cdot 1$

Co TC

( $I \cdot I \cdot I$

GO IO 4

c

NETION-RAPBSEN MEIRED FER GELPING BOU 10

$6 Q=I \circ G \Leftrightarrow(I(2)-I) Y(4)) \cdot B=(I(6)-I=Y(8))$

$\mathbf{I}=\mathbf{X}=\mathbf{A} / \mathbf{Q}$

$\mathbf{E} \cdot \mathbf{I} \cdot \mathbf{1}$

C NOT TO BICEED BOIB ITBRATION

IF (I.GT.B) 0 TO 7

OO TO 4

$7 \mathrm{~B}(M)=\mathrm{I}$

$A-E X P(-X * Z \in D E L)$

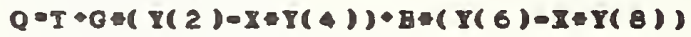

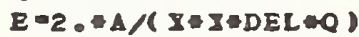

$Z(M)-E H(I(2)-I(6)-X+\nabla 2 \div(I(1)-I(5)))-A B$

$P(M)=E A C E A D$

$R(U)-E \oplus \Delta C=(I(2)+I(6)-I=\nabla 1-(I(2)-I(5)))$

IF ( $I$ ETEEL.GT.30.) RETORN

IF $(M .5 Q .60)$ REIORN

$\mathbf{I}=0$

IF (M.GI.1) GO IO 1

IF $(I . G T \cdot .5)$ GO IE I

$F=3.5$

$\mathrm{v}=.002$

$1 \mathrm{I}=\mathrm{I} \cdot \mathrm{O}$

CALL ABC( $I, I, J, I)$

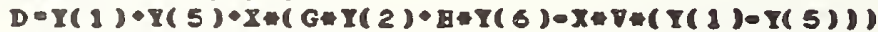

IF $(M . E Q .1) E=I / 4$.

IF $(M . G T .2) B=(I-B(M-1)) / P$

$M \cdot M \cdot 1$

$\mathbf{I}=\mathbf{X} \cdot \mathbf{E}$

00 TO

END 


\section{FEDERAL INFORMATION PROCESSING STANDARD SOFTWARE SUMMARY}

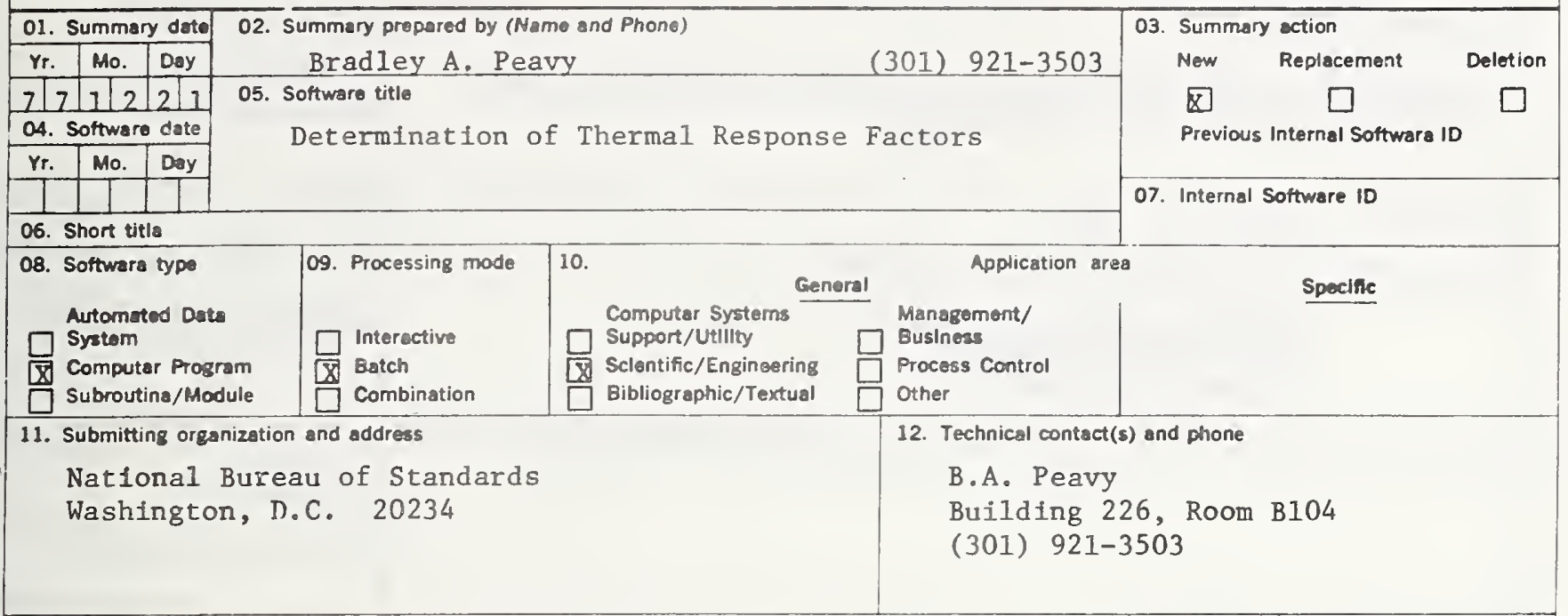

\section{Narrative}

Program computes thermal response factors of multi-layer building constructions (one to seven layers) for thermal conduction applications. Provision is made for including or excluding surface film thermal resistances. Input includes time increment ( 1 hour, $1 / 2$ hour, etc.), number of layers, thermal properties and descriptions of each layer. Output includes the thermal response factors, $X, Y$ and $Z$. Main program is amendable to use as a subprogram in a larger program for use in thermal conduction applications.

\section{Keywords}

Dynamic conduction heat transfer, thermal response factors

\begin{tabular}{|l|l|l|l|}
\hline $\begin{array}{l}\text { 15. Computer manuf'r and model } \\
\text { UNIVAC } 1108\end{array}$ & 16. Computer operating system & 17. Programing language(s) & $\begin{array}{c}\text { 18. Number of source program state- } \\
\text { ments }\end{array}$ \\
\hline 19. Computer memory requirements & $\begin{array}{c}\text { 20. Tape drives } \\
\text { None }\end{array}$ & 21. Disk/Drum units & None \\
\hline
\end{tabular}

23. Other operational requirements

24. Software availability

Available

区.
Limited

$\square$
In-house only

$\square$
25. Documentation availability

Available $\square$ Inadequate
In-house only

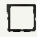

26. FOR SUBMITTING ORGANIZATION USE 
NBS-114A (REV.7-73)

\begin{tabular}{|c|c|c|}
\hline \begin{tabular}{c|c} 
U.S. DEPT. OF COMM. & 1. PUIBIIC ATION OR REPORT NO. \\
BIBLIOGRAPHIC DATA & NBSIR 77-1405 \\
SHEET &
\end{tabular} & $\begin{array}{l}\text { 2. Gov't Accession } \\
\text { No. }\end{array}$ & 3. Recipient's Accession No. \\
\hline \multirow{2}{*}{\multicolumn{2}{|c|}{$\begin{array}{l}\text { 4. TITLE AND SUBTITLE } \\
\text { DETERMINATION AND VERIFICATION OF THERMAL RESPONSE FACTORS } \\
\text { FOR THERMAL CONDUCTION APPLICATIONS }\end{array}$}} & $\begin{array}{l}\text { 5. Publication Date } \\
\text { April } 1978\end{array}$ \\
\hline & & 6. Performing Organization Code \\
\hline 7. AUTHOR(S) Bradley A. Peavy & & 8. Performing Organ. Report No. \\
\hline \multicolumn{2}{|l|}{$\begin{array}{l}\text { 9. PERFORMING ORGANIZATION NAME AND ADDRESS } \\
\text { NATIONAL BUREAU OF STANDARDS } \\
\text { DEPARTMENT OF COMMERCE } \\
\text { WASHINGTON, D.C. } 20234\end{array}$} & $\begin{array}{l}\text { 10. Project/Task/Work Unit No. } \\
4626528 \quad(7426528) \\
\text { II. Contract/Grant No. }\end{array}$ \\
\hline \multirow{2}{*}{\multicolumn{2}{|c|}{ 12. Sponsoring Organization Name and Complete Address (Street, City, State, ZIP) }} & $\begin{array}{l}\text { 13. Type of Report \& Period } \\
\text { Covered } \\
\text { Final }\end{array}$ \\
\hline & & i4. Sponsoring Agency Code \\
\hline
\end{tabular}

15. SUPPI.EMENTARY NOTES

16. ABSTRACT (A 200-word or less factual summary of most significant information. If document includes a significant bibliography or literature survey, mention it here.)

New formulas for calculating thermal response factors for multiple-1ayer construction have been developed by a rigorous derivation. A comparison was made of the time for computation between the presently used matrix algebra method and the method given in this paper. Results were obtained using the new method in one-fiftieth to one-half of the computational time necessary to obtain solutions from the matrix algebra method.

Comparisons with another analytical method were performed to verify the accuracy of the response-factor technique.

17. KEY WORDS (six to twelve entries; alphabetical order; capitalize only the first letter of the first key word unless a proper name; separated by semicolons) response factor; verification.

Dynamic conduction heat transfer; heat transfer; thermal

\footnotetext{
18. AVAILABILITY $\quad$ Unlimited

For Official Distribution. Do Not Release to NTIS

7 Order From Sup. of Doc., U.S. Government Printing Office Washington, D.C. 20402, SD Cat. No. C 13

\begin{tabular}{|l|l|}
\hline $\begin{array}{l}\text { 19. SECURITY CLASS } \\
\text { (THIS REPURT) }\end{array}$ & 21. NO. OF PAGES \\
UNCLASSIFIED & 22. Price \\
\hline $\begin{array}{l}\text { 20. SECURITY CLASS } \\
\text { (THIS PAGE) } \\
\text { UNCLASSIFIED }\end{array}$ & USCOMM-DC 29042.P74
\end{tabular}



